\title{
Effects of oxygen concentrators on ventilator oxygen delivery
}

\author{
Les Walker • Merna Bee, RRT $\cdot$ Robert M. Friesen, MD
}

Received: 30 January 2010/Accepted: 13 April 2010/Published online: 4 May 2010

(C) Canadian Anesthesiologists' Society 2010

\section{To the Editor,}

As previously detailed, ${ }^{1,2}$ there are more than 50 hospitals in Canada that utilize oxygen concentrators (OCs) as their primary source of oxygen supply. Furthermore, on evaluating $\mathrm{OC}$ technology as a primary oxygen source, the US Food and Drug Administration ruled in 2004 that hospital grade OCs were classed as a substantial equivalence to United States Pharmacopeia (USP) oxygen $93^{\mathrm{A}}$ $\left(\mathrm{O}_{2}\right.$ 93) and therefore subject to compliance of all of the same federal statutes and regulations. Guidelines to the Practice of Anesthesia ${ }^{3}$ provides consideration for the use of OCs with an anesthetic machine and includes topics such as anesthesiologists' awareness of the OC, monitoring circuit oxygen concentration, machine calibration with $\mathrm{O}_{2}$ 99, and understanding the potential for argon accumulation at fresh gas flows $<1 \mathrm{~L} \cdot \mathrm{min}^{-1}$. The increasing use of anesthesia workstations and computer-controlled patient ventilators prompted us to examine the circuit oxygen delivery of these systems with an OC as a primary source of supply.

As a benchmark study, we tested the following two anesthetic machines: the Aisys Carestation ${ }^{\mathrm{TM}}$ (GE Healthcare, Madison, WI, USA) and the Narcomed 2B (North American Drager, Telford, PA, USA). In spite of its age, we included the Narcomed $2 \mathrm{~B}$ as it still functions in some local outpatient facilities. We also tested the following two patient ventilators: the Puritan Bennett model $840^{\mathrm{TM}}$ (PB 840) (Nellcor Puritan Bennett, Boulder, CO, USA) and the LTV® 1000 (Pulmonetics, Minneapolis, MN, USA). Oxygen 93 was obtained by pre-filling E-size oxygen cylinders with an $\mathrm{OC}$ filling station, Chad Total $\mathrm{O}_{2}$

L. Walker · M. Bee, RRT · R. M. Friesen, MD $(\bowtie)$

Peace Arch District Hospital, White Rock, BC, Canada

e-mail: robert.friesen@fraserhealth.ca
Delivery System $^{\text {TM }}$ (CHAD Therapeutics Inc., Chatsworth, CA, USA), and then the $\mathrm{O}_{2} 93$ was supplied to each system via a high pressure regulator. Oxygen 99 and medical air were supplied via a hospital wall outlet. Each system was tested for circuit oxygen levels at decreasing increments in the same sequence, $\mathrm{O}_{2} 99$ followed by repeat observations with $\mathrm{O}_{2}$ 93. In addition to each system's built-in oxygen sensor (except for the LTV 1000 that utilizes a mechanical blender), oxygen was also monitored with an in-line monitor, Mallinckrodt PTS $2000^{\mathrm{TM}}$ (Nellcor Puritan Bennett, Boulder, CO, USA). A Smart Lung ${ }^{\mathrm{TM}} 600$ test lung (IMT Medical BuchoSG, Switzerland) was utilized. The standardized ventilator parameters were tidal volume $400 \mathrm{~mL}$ and a frequency of ten cycles per minute. Oxygen concentration measurements were made at machine settings of $30-100 \%$ oxygen in increments of $10 \%$. At each increment, measurements were recorded only after attaining five minutes of steady-state values on the PTS 2000. Machine calibration, both manual and automatic, were from the hospital primary supply $\left(\mathrm{O}_{2} 99\right)$ prior to each study.

The aim of this study was to observe any differences between the inspired oxygen settings of the ventilator or anesthetic machine and the actual circuit oxygen levels when using two different oxygen supplies $\left(\mathrm{O}_{2} 99\right.$ vs $\left.\mathrm{O}_{2} 93\right)$. Secondarily, we were interested in the general ventilator and alarm function with the presence of $\mathrm{O}_{2} 93$ as a primary source of supply. At each oxygen setting (30-100\%, $n=8$ ), the PTS 2000 recording was subtracted from the percent oxygen setting on the test machine. A negative value indicated that the machine setting overestimated the actual oxygen present. The mean differences between $\mathrm{O}_{2}$

\footnotetext{
A The United States Pharmacopeia. The National Formulary. Rockville, MD, United States Pharmacopeia Convention Inc, 1998: IV/360.
} 
Table 1 Inspired oxygen settings $v s$ actual values

\begin{tabular}{lccccl}
\hline Machine & $\mathrm{O}_{2} 99^{*}$ & $\mathrm{SD}$ & $\mathrm{O}_{2} 93^{*}$ & $\mathrm{SD}$ & Student's $t$ test \\
\hline Drager 2B & -1.6 & 0.9 & -1.6 & 1.1 & $P=0.450$ \\
Aisys Carestation & -0.3 & 0.4 & -0.5 & 0.4 & $P=0.237$ \\
PB 840 & -0.7 & 0.9 & -1.7 & 0.9 & $P=0.322$ \\
LTV $1000^{\dagger}$ & -0.9 & 1.8 & -3.1 & 2.8 & $P=0.004$ \\
\hline
\end{tabular}

$\mathrm{SD}=$ standard deviation. $*$ Difference between actual oxygen percent (PTS 2000) minus machine setting (mean values, $n=8$ ); a negative value indicates a measured oxygen less than the machine setting. ${ }^{\dagger}$ LTV 1000 inspired oxygen setting (not an actual measured value). An oxygen blender meters oxygen flow by measuring oxygen inlet pressure

99 and $\mathrm{O}_{2} 93$ at each setting were compared for each machine and analysed by Student's $t$ test.

Table 1 is a summary of the observed mean differences. Observations at the sequential oxygen settings were pooled, as each machine was tested in the same manner. Additionally, we noted that the contribution of $\mathrm{O}_{2} 93$ was more evident at higher $\mathrm{F}_{\mathrm{I}} \mathrm{O}_{2} \mathrm{~s}$. The mean difference at a $30 \%$ oxygen setting was $0.1 \% \pm 0.47$, while the mean difference at a $100 \%$ oxygen setting was $2.8 \pm 1.9$ $(P=0.03)$. In general, the machine settings slightly overestimated the actual circuit oxygen concentration, and, except for the LTV 1000, these were not statistically significant changes. All of the ventilators functioned within specification for either oxygen supply. No alarm functions were triggered by the use of USP $\mathrm{O}_{2} 93$ during any of the test runs. For the systems that provided in-line circuit oxygen monitoring, Aisys Carestation, Narcomed 2B, and PB 840, there was an insignificant difference between selected and actual oxygen concentration for either source of oxygen supply.

Although of minimal clinical significance, the LTV 1000 demonstrated $>3 \%$ negative difference between the actual measured circuit oxygen concentration and the ventilator setting. It would be prudent to monitor in-line
Table 2 Oxygen sensor performance specifications*

\begin{tabular}{llll}
\hline Machine & Oxygen Sensor $^{\dagger}$ & Accuracy & Notes \\
\hline PB 840 & EnviteC - Wismar & $\pm 1.0 \%$ & \\
$\begin{array}{l}\text { Aisys } \\
\quad \text { CareStation }\end{array}$ & Datex Ohmeda & $\pm 2.5 \%$ & $\mathrm{FGF}^{*}>1 \mathrm{~L} \cdot \mathrm{min}^{-1}$ \\
Narcomed 2B & $\begin{array}{c}\text { MaxTex } \\
\text { (MAX 11) }\end{array}$ & $\pm 1.0 \%$ & $\mathrm{FGF}^{*}>1 \mathrm{~L} \cdot \mathrm{min}^{-1}$ \\
& & 5 min equilibration \\
PTS 2000 & & $\pm 2.0 \%$ & $\begin{array}{c}\text { Annual factory } \\
\text { calibration }\end{array}$ \\
\hline
\end{tabular}

* Product manufacturers' information appears in the text. ${ }^{\dagger}$ All oxygen sensors specified calibration with $100 \%$ oxygen. Sensor components of a different model name than the actual medical device are listed here. ${ }^{*}$ Total fresh gas flow

oxygen concentration on all ventilators regardless of their source of oxygen supply.

The differences observed in this study fall within manufacturer supplied oxygen sensor specifications (Table 2).

In conclusion, we did not observe any adverse ventilator function utilizing either $\mathrm{O}_{2} 93$ or $\mathrm{O}_{2} 99$. Furthermore, there were no clinically significant differences between machine settings and actual measured oxygen concentration when using an OC as a primary source of supply.

Competing interests None declared.

\section{References}

1. Friesen RM. Oxygen concentrators and the practice of anaesthesia Can J Anaesth 1992; 39: R80-9.

2. Friesen $R M$, Raber $M B$, Reimer $D H$. Oxygen concentrators: a primary oxygen supply source. Can J Anesth 1999; 46: 1185-90.

3. Merchant $R$, Bosenberg $C$, Brown $K$, et al. Guidelines to the Practice of Anesthesia, Revised Edition 2010. Can J Anesth 2010; 57: 58-87. 